\title{
PURSUING IMPERFECTION, FORGIVENESS, AND REPENTANCE IN POPULAR TWENTY-FIRST CENTURY MALAY TELEVISION FICTION
}

\author{
Mohd Muzhafar Idrus \\ Universiti Sains Islam Malaysia \\ muzhafaridrus@usim.edu.my \\ Raihanah M. M. \\ Universiti Kebangsaan Malaysia \\ raihanah@ukm.edu.my \\ Ruzy Suliza Hashim \\ Universiti Kebangsaan Malaysia \\ ruzy@ukm.edu.my
}

\begin{abstract}
Since the turn of the twenty-first century, popular Malay television fiction has been thriving and gaining popularity. Through staggering online reruns, this sheer popularity broadens the expanse of multifaceted issues. This paper contextualizes popular TV fiction within a space of imperfection, focusing on audience responses to Julia, Adam E Hawa, and About Dhia. Using the lens of democratic habits of mind according to Mezirow: "respect for others, self-respect, willingness to accept responsibility for the common good, willingness to welcome diversity and to approach others with openness," this paper reveals two of the many emerging themes, namely, forgiveness and repentance, which can intensify possibilities for acknowledging human faults, vulnerability, and imperfection between the private/public and self/society. By considering reactions of some of the many popular TV fiction audience, this paper presents unfolding, interactive twenty-first-century insights into what it means to pursue an imperfect duty, whose responsibility could be understood in the sense of forgiveness and repentance.
\end{abstract}

\section{Keywords}

Islam; Malaysia; Malay culture; popular culture; Psychology; TV Fiction 


\section{About the Authors}

Mohd Muzhafar Idrus is an assistant professor at Faculty of Major Language Studies, Universiti Sains Islam Malaysia. He is currently involved in research related to advice-giving, discourse analysis, and literary studies.

Raihanah M. M. is an associate professor of literary studies at the Faculty of Social Sciences and Humanities, Universiti Kebangsaan Malaysia. She recently received a university grant to investigate the representation of imperfection in popular culture.

Ruzy Suliza Hashim is professor of literature at the School of Language Studies and Linguistics, Faculty of Social Sciences and Humanities, Universiti Kebangsaan Malaysia (UKM). She is the Deputy Director for Planning, Operation \& Quality at Centre for Research and Instrumentation Management (CRIM), Universiti Kebangsaan Malaysia.

Kritika Kultura 33/34 (2019/2020): 456-475

(c) Ateneo de Manila University

<http://journals.ateneo.edu/ojs/kk/> 


\section{INTRODUCTION}

Discourses of perfection have always been an important symbol in literary readings, lending credence to constant re-evaluation of human moral capacity and individual's preservation and enrichment in twenty-first century's literary studies. Perfection is usually framed within the many spaces of ideals, goodness, triumphs, achievement, and what is logical and normal. Norm deviancy and human faults, on the contrary, are roots of evils and are frowned upon as they are unique and irreplaceable (Poser 10). They are usually portrayed as sources of imbalance, disinclination, unpredictability, and dullness. Such imperfection, a misalignment between what society expects and what is presented in human lives could disclose many dimensions-rational, spiritual, moral, and cultural. Imperfection is usually associated with stagnation, failure, suffering, and shame. Socio-political orientations, ideologies, and schemata, just to name a few, often times become sets of fixed assumptions and expectations, reifying the demarcation between perfection or otherwise (Scarre 1022). Imperfection, authorial-defined or not, serves as a focal point of scholars' interests because it accentuates the extent to which what is normal/abnormal changes as culture evolves (Hadad and Schachter 854). One factor that has been observed and that continues to be relevant in explaining (im) perfection is with regard to how human lives are shaped and transformed by cultural subjectivities. As Bradford and Clark argue, faults and deviation remain enmeshed in society as "aspects of tradition continue to shape lived experience, played out in particular, local, and nuanced ways. Its scope and impact is contingent on a range of specific factors: history, culture, place, and so on" (196). Regardless of content and medium, our consciousness of imperfection sees perfection to be affirmed and molded, dignified in the image of social duty and religious norms. Frustrations, despair, desire, faith, hope, hopelessness, and happiness often present "windows" into human beings' living condition, complete or otherwise. While it is not the intention to portray imperfection in negative, cautious light or (re)packaging it as a symbol of ignorance or consequences of sociocultural risks, imperfection, on the contrary, facilitates a space for representing counter-narratives to what is considered natural, complete, and accepted. Scrutinizing what is perfect or imperfect often reflects the interest of society as it is not "just a market enterprise or some sporadic of being deviant, of being essential troublemakers, but rather that cultures can and should be read" (Johansson and Lalander 1079) as central to doing imperfection. Put differently, studying imperfection often leads to recurring snapshots in which vulnerability, human virtue, and moral responsibility co-exist, presenting a more nuanced and complex "catalogues" to human connection to one another.

One of the depictions is where and when imperfection is portrayed, within noninstitutionalized, non-state-endorsed, twenty-first century, everyday experience. A 
feasible way of elaborating imperfection is through describing popular television fiction (hereafter, TV fiction) and its audience. With the aim of studying how audience members interrogate familiar issues such as cultural identity in particular to social and cultural understanding of humanities with which they identify on popular TV fiction, imperfection in this paper is illuminated through audience responses. The key to describing imperfection in audience narratives, we argue, lies in the idea of how they navigate issues of imperfection using the lens of democratic habits of mind. The notion of "democratic habits of mind" is often examined within personal, transformative spaces, and we wish to draw on this idea to recontextualize and extend its deployment to show how audience members relate to popular TV fiction. Audience responding to popular TV fiction, as we shall see, tells particular stories on perfection. On the one hand, perfection sees individual conditions of spirit, mind, and society; on the other hand, imperfection relies on individual's truly "free," "unique, untraveled path" (Poser 17). In what follows, we will explain how democratic habits of mind is contingent to our discussion; of the complex links between audience member voices and their engagement with three popular Malay TV fiction which have since drawn over 11 million viewers ("Annual Report") and 120 million online views ("Tonton Statistics"), namely, Julia, Adam \& Hawa, and Tentang Dhia (hereafter, About Dhia). Across the board, we highlight forgiveness and repentance as two of the many emerging themes, although we acknowledge other issues arising from this project are equally, deservingly important to be captured. The recurring, recirculating theme of forgiveness and repentance as an insistence captures our wonder and intrigue as dimensions of imperfection, warranting increasing attention from literary scholars. In this sense, audience responses present insights into unfolding and often reflexive "window" into particular works of fiction, between a variety of private and public spaces. As such, the discussion on audience responses to popular TV fiction, as will be illustrated, will tell particular stories about what it means to exhume human "faculties for intersubjectivity, reflective discourse," and civic-mindedness (Mezirow 15), stories that examine unofficial accounts of audience members concerning imperfection.

Nevertheless, our readings on audience member responses elaborated in the following pages cannot be assumed as prominently representative of all audience members, watching all popular Malay TV fiction. Instead, participants who were recruited in the north of Peninsular Malaysia articulated their reactions solely based on how they relate to Adam \& Hawa, Julia, and About Dhia. These responses, in addition, serve as a rough guide in the selection of readings that can best manifest their self-understanding and self-reflexiveness of their engagement with popular $\mathrm{TV}$ fiction, making these stories as some of the many stories from our project that can be told regarding imperfection within popular Malay TV fiction spaces. As such, Chua Yan Piaw argues, qualitative insights cannot be generalized "on another group of subjects even though they possess similar characteristics" (188). Rather, their 
responses can only be discussed and understood by acknowledging these contexts that gesture towards the ways in which the self and relations of imperfection are visible. It is the contention to integrate literary works (read: popular TV fiction) we find occupying a dominant role in raising sociocultural consciousness, in the hope that they continue to be important sites to unveil shifting terrains in twenty-first century literary studies.

\section{A GLIMPSE INTO LENS OF DEMOCRATIC HABITS OF MIND}

Before we get into elaboration of imperfection as highlighted in audience responses, it is useful at this juncture that the lens of democratic habits of mind is discussed. While readings on this lens have been widely deliberated, a comprehensive, definitive account of it goes beyond the focus of this paper. Nevertheless, the following readings could be surmised. Democratic habits of mind is a concept to describe how individuals participate in discourse dimensions within humanity settings. According to Jack Mezirow, "respect for others, self-respect, willingness to accept responsibility for the common good, willingness to welcome diversity and to approach others with openness" (14) are principles exemplified in subjective, adult learning. Mezirow adds, "openness to alternative points of view: empathy and concern about how others think and feel" (14) form multiple perspectives that add to one common ground value of strengthening bonds among people. While these are perspectives embedded in the ideas of active listening, flexibility, reciprocity, and cooperation, it reflects tolerance, equality, and rationality. Fostering this discourse in literary studies will transpire an active dialogue, uncovering "the meaning of an experience" (Mezirow 14). Accentuating agency (Jarvis 4), multiculturalism (Chang 188), cultural diversity (Lämsä and Sintonen 107), ecology (Walter 25), and sexuality (Trimble 52), just to name a few, are some of the many studies which have benefited from this lens. However, how is perspective of democratic habits of mind elaborated in popular TV fiction's audience member responses, given the changing and demanding landscape of twenty-first century settings?

This article argues that, as audience members engage with popular TV fiction, their responses invariably entail a discussion on forgiveness and repentance in their oral reactions. From watching, reflecting, and analyzing issues in Julia, About Dhia, and Adam \& Hawa, audience member reactions point to the anchors of empathy and compassion. It is this opportunity that overlaps with Mezirow's lens of democratic habits of mind in which it presents an alternative model of justice vis-à-vis forgiveness and repentance when and where everyone, perfect or otherwise, guilty or not, has equal opportunity to participate in a space of respecting and recognizing dignity (Mookherjee 1066). In the midst of violent, 
chaotic sociocultural realities in the twenty-first century, democratic habits of the mind could provide "windows" into love of the world and draw on elements of reconciliation. With this lens, imperfection, through forgiveness and repentance, provides for individuals with an opportunity of telling their stories, demonstrating their commitment to a project of moral and cultural self-improvement.

In the remainder of this paper, we hope to contribute to this dialogue on imperfection and elaborate its links to shifting dimensions of literary studies. Joachim Stoeber in his book, Psychology of Perfectionism, calls for insights into intricacies of perfection that elaborate on the conception of self and its vulnerabilities. Central to this understanding is what he termed as "expectations and experiences" (Stoeber 340). These experiences, he adds, must center on "conception of the self" and "expectations" that are "primarily self-focused" (Stoeber 344). In what follows, our objective is to further delineate aspects that dominate audience responses through the lens of democratic habits of mind and operate its relevance to the notion of imperfection. At this point, we will recontextualize this lens to suggest that popular TV fiction provide audience with spaces to deploy varying, multifaceted practices of the self, and to explore some of the many examples of what it means to deal with shame, guilt, and vulnerability. In other words, audience responses reacting to imperfect worlds may explain the connectivity between self, identity, and resilience.

That said, although this lens carries ideological accretions of Western discourse, it is argued that regardless of any perspectives, "western-derived or not," it will provide "a way of seeing things in a particular light of tentatively arranging things in particular configurations in order to comprehend accompanying relational constructions. Each discerning position has its own advantages and disadvantages" (Hashim 14). Similarly, to combine democratic habits of mind into this study will clarify our thoughts on the significance of imperfection, raising consciousness of humankind's internal strength against the odds. By employing this lens, audience responses will demonstrate the many ways self-understanding and others' assumptions are in conflict, allowing a new beginning to surface across the many experiences of popular TV fiction at home, in school, and in society.

\section{FORGIVENESS, REPENTANCE, AND MALAY CULTURAL IDENTITY DISCOURSE}

As we have set out to mention at the outset, imperfection vis-à-vis forgiveness is emergent to our audience responses; therefore, the notions of forgiveness and repentance that are contextualized within Malay cultural discourse need some exploration. While a definitive, comprehensive reading of forgiveness and repentance goes beyond the scope of the paper, a number of readings exist. 
Forgiveness is encapsulated within and beyond Malay adat (customs). Malay adat comprises tradition, religion, and cognitive understanding. Malay adat which highlights values of harmony is so important (Idrus et al. "Imagining" 218; Provencher 205-206) that any attempt to disrespect Malay adat may result in severe consequence (Banks 583; Idrus et al. "Malay" 6). Firstly, because harmony is fundamental, the values of politeness and keeping disagreements ensue. The richness in folktales may explain some of the many reasons why forgiveness accentuates one's adhesion to compromise, tolerance, and modesty (Idrus et al. "Globalization" 34; Idrus et al. "Rediscovery" 213). While the aim is to "uphold peace and harmony in their relationship" (Zainal 15), forgiveness within Malay landscape encourages Malays to be "sensitive" and "gentle in nature" (Zainal 4), ensuring their minimal involvement in war or violence. Secondly, regardless of gender and social roles, repentance within Malay cultural realms is observed (Idrus 28). Specifically, repentance which is linked to sinfulness is often regarded as the ultimate forgiveness asked from God. Within the Malay world, two spectrums can be seen as far as repentance is magnified. Firstly, "God's infinite goodness posits mercy, forgiveness and benevolence" and secondly, "His wrath and severe, strict and unrelenting justice" (Idrus et al. "Rediscovery" 213). More broadly, forgiveness and repentance form the Malay-oriented scheme of work; forgiving others is a human virtue.

In what follows, we will illustrate and recontextualize some of the many ways concepts of imperfection is relatable to audience responses reacting to popular $\mathrm{TV}$ fiction. Through forgiveness and repentance, audience reactions provide unofficial accounts of what it means to be responsible for their good and bad deeds. Reconciliation, providing accountability for past actions, undoing sins one has perpetrated, extending streams of compassion and celebration, entailing closure and repression of memory, just to name a few, are but some trivial insights that could be learned from audience stories of their engagement with popular TV fiction. The many contexts, including but are not limited to scenes on self-(re)construction and (re)projection, stage a story through which individuals escape "oppressive guilt, self-hatred, and withdrawal from a distrustful world" (Klein 73) that may disrupt our normal ways of examining imperfection in popular culture studies imaginable. Forgiveness and repentance, as we shall see, not only offer a key point unlocking a point of departure to "suffering and endless human shortcomings" (Poser 162), but also a reinforcement of healing and reparation, as well as unity and homogeneity. Bearing in mind these cultural subjectivity tenets within Malay world dimensions, the setting of audience member responses in which imperfection is made visible is revealed as an important principle in our readings. 


\section{SUMMARY OF POPULAR TV FICTION}

As mentioned above, audience members respond to how they relate to Adam $\mathcal{E}$ Hawa, About Dhia, and Julia. In this section, a summary of popular TV fiction is presented to retrieve the narratives in which the characters experience their lives, the different influences, preservation of, and resistance to rules the Malay-Muslim traditions have prescribed for their behavior. Whether these characters allow audience members to experience despair, happiness, or complete faith, their display of becoming rational, moral human beings can be made visible. Put differently, the summary provides "windows" into the interactions in which the characters are seen as imperfect, both in their own and others' eyes.

\section{Adam \& Hawa}

Adam $\mathcal{E}$ Hawa is a story revolving two major characters, Ain and Adam. While working for a kindergarten, Ain gets acquainted with Adam. Spending time and going out together, Ain sees another side of Adam: his wild encounters with other women at bars. Having realized this, Ain continues to work instead. One night, however, Ain is caught unlawfully in bed, in close proximity with Adam by local towners and religious officers. Charged with khalwat (close proximity with unmarried partner) ("Awrah"), Ain, later, is involved in a forced marriage with Adam. Ain further holds grudges, being revengeful of Adam's silence the night she is arrested. Having difficult times accepting Adam as husband, Ain forgets Adam and decides to partake higher education classes in Sydney, Australia. Subsequently, when Ain performs Hajj, she encounters Adam. As Adam confronts Ain, Adam apologizes and repents, asking for a reconciliation to which Ain agrees.

\section{About Dhia}

Zikir, Rafie, Azmi, Melli, and Dhia are central characters in About Dhia. While Rafie shows his profound feelings towards Dhia, Dhia marries Azmi instead. Despaired, Rafie experiences this breakup very badly; he starts socializing with girls at a nearby bar in which Melli is a regular. As Melli resents Dhia, Melli tackles all men Dhia currently dates and has dated, including Rafie. After weeks of seducing Rafie, Melli now plans to sleep with Azmi. Successful, they are, however, quickly discovered by religious authorities and Dhia quickly hears the news. Because her days of marriage to Azmi are fast approaching, Dhia ignores his "infidelity" and ultimately forgives Azmi. Soon, while Melli is pregnant, she further gatecrashes 
Dhia's wedding and insists that Azmi be held accountable for the baby she carries. After hours of jostling and involving in verbal altercation with Melli, Dhia raises the red flag and insists Melli be married to Azmi instead. Later, Dhia is introduced to Zikir. As Zikir accords his affection for Dhia, Dhia agrees to get married to Zikir. The relationship, later, goes awry. As Zikir's mother and Dhia have unpleasant encounters with each other, Zikir has no choice but to offer Dhia two choices: to have Dhia out of the house or to have Dhia agreed to a polygamous relationship. Stressed out, Dhia agrees to remain in a polygamous relationship. Months later, as Zikir discovers his mother's use of witchcraft to possess him to hating Dhia, Zikir leaves the older woman and apologizes to Dhia. Diagnosed with a terminal cancer, Dhia forgives and blesses Zikir's subsequent marriage.

\section{Julia}

Julia is a story involving central characters named Julia, Amir, and Azwan. Having met and dated in Seoul, Amir and Julia return to Malaysia in bad shape. Tension escalates when Julia's parents aggravate her about marriage while Julia concentrates on becoming an engineer. Amir, however, decides to marry Nurain, a florist. As news of Amir marrying Nurain travels to Julia, Julia chooses to remain alone. Later, Julia is acquainted and subsequently married to Azwan. Their marriage, however, does not go as planned. Azwan's mother hates Julia and relies on black magic, influencing Azwan to become violent toward Julia, forcing Julia to file for a divorce and move out of the house. Having separated for a couple of years, Julia, finally, forgives them both.

\section{CURRENT STUDY: VOICES OF AUDIENCE MEMBERS}

The following section elaborates methods used in our study. As mentioned above, readings reported here relating to what can be learned regarding imperfection are part of a bigger study; they do not represent readings of an entire examination between audience members and popular TV fiction spheres. What will be seen in the following sections is the summary of focus group projects, involving the ways in which interviews were carried out. It begins by describing participants involved. Process and procedure for gathering these responses, including the process for rereading and analyzing the responses, will also be examined. By doing so, the ways in which audience responses and popular TV fiction overlap are revealed. 


\section{Participants}

Focus group interviews were carried out among twenty-six participants between the age of 18 to 24 (mean age: 21 ) but only twenty-four of them, divided into three groups, were taken for final analysis. The first focus group discussion was recorded at a local council hall, consisting 17 to 21-year-old participants (six females), while the second group discussion, consisting other 18 to 20-year-old participants (six females), took place at local community college. Another six females, aged 19 to 24 years old, participated in the third focus group discussion which was held at a sports complex. Of these, some studied in order to gain credits to fulfill military retirement exercise, while some others sat for community college to obtain certification. (Office) assistants and unemployed females constitute the background for other participants. Ranging from three districts in one of the states in the north of Peninsular Malaysia, some of the participants somewhat knew each other in some capacity, as many participants named their friends as participants, enlarging the friendship circles. Because it presented insights into varying, multiple experiences to be shared and opinions to be exchanged, the broad characteristics of the focus group participants was important. Either staying at home or performing business at work, their insights into popular TV fiction accentuated dynamic corroboration between the TV fiction they watch and their responses. These diverse, sociocultural backgrounds of audience members, as Piaw succinctly expressed, are "useful in collecting information about a specific issue," allowing "more information" to be obtained (149). Notice boards, emails, and listserv were some of the many ways calls for volunteers that read, "Malay volunteers who watched Julia, About Dhia, or Adam \& Hawa" were distributed at a local council and college community in the north of Peninsular Malaysia. Through an informant and repeated phone calls, we were able to recruit and locate participants within a number of months, although it was rather challenging to do so at the beginning. Although other framework(s) exist, purposive and snowball procedures were used in this study as they gather participants who have "certain characteristics" (Piaw 43). In realizing the goal of this inquiry, we were guided by the principle that the goal was to learn the ways in which popular TV fiction can unveil imperfection as expressed in audience member accounts. It is, therefore, not the intention of the paper to solely describe reactions of all participants watching all popular Malay TV fiction, rather, our study "is couched in terms of the generalizability of cases to theoretical propositions" (Bryman 90). While this approach cannot present insights into exhaustive and definitive interpretation of participant accounts, the following readings serve as a rough guide in elaborating what it means to compose and re-compose experiences with im/perfect world(s). 


\section{Procedure}

A set of protocols guided the focus group interviews. After interviewees were briefed on disclosure and consent, they were told that the interview would last somewhere between 40-45 minutes and that they were permitted to start, pause, and finish at their convenience. Through framework of thematic life story (Hadad and Schachter 858), interviewees were able to describe their story of watching popular TV fiction simultaneously making links to some of the many sociocultural issues. This framework, which is grounded in audience member's discussing flexibly on the issues of popular TV fiction, allows participants to simultaneously link their stories to a specific theme. The specific theme was on sociocultural issues and its sub-association concepts. If participants were not able to speak of these issues, interviewers asked a number of questions such as "What aspects of adat (customs) do you observe?" "Could you explain in detail?" "What event in popular TV fiction do you relate to, Malay customs or modern-related issues, or can you describe some other cultural issues you see coming?" "What traditional/conservative issues can you relate to in these TV fiction?" "What issues on modernity can you identify with in these TV fiction?" While questions were adapted (Idrus et al. "Rediscovery" 215), the ways in which discussion took place were unstructured, as such "flexibility took control of the uniqueness of the specific case" (Eisenhardt 549). Through these steps, audience's lived experience with popular TV fiction was explored (Hadad and Schachter 858).

\section{ANALYSIS}

It was impossible to interpret the interviews using a singular approach (Alasuutari 4). After interviews were recorded and transcribed, the interpretation took a dynamic, fluidic turn, as interpretation called for varying levels of reading (Alasuutari 17). Through multiple, repeated readings to ensure comprehension, excerpts in which participants made connections to popular TV fiction allows room for emerging phrases, expressions or ideas, that are connected to wider spaces of society and culture. The following section expands on this by demonstrating two of the many emerging themes from participants' interviews.

\section{Forgiveness and Reconciliation}

This section describes audience responses to popular TV fiction. While reacting to popular TV fiction, scenes illustrating forgiveness illuminate some of the many 
stories of the selves, dealing with human faults, vulnerability, past guilt, and misdeeds that broaden the cleavages of imperfection. In the following elaboration, many participants in our study are quite concerned about the connections made to forgiveness as a point of reconciliation. To a certain extent, a majority of the participants employed popular TV fiction's depictions of imperfection vis-à-vis religious sensibilities or ignorance as illustrated by characters in popular Malay $\mathrm{TV}$ fiction in order to exercise visceral understanding of forgiveness within MalayMuslim framework. In other occasions, as we shall illustrate, some responses point to the often vicarious encounters these participants have with the stories they are engaged with; forgiveness was one of the recurring aspects to which they can relate and describe:

I think forgiveness allows us to connect with one another. As Rafie apologizes, I can allow my children to learn that although one drinks and perpetrates crimes, the door to forgiveness is always open, allowing one to get closer to God (21-year-old, unemployed).

I cannot even call myself religious-conscious, I am not even close to practicing and praying. But I have come to terms with Islam after watching Adam \& Hawa that it is okay to practice religion in moderation. Through Adam $\mathcal{E}$ Hawa, the change I am embracing is not easy, but I am okay with where I am right now (23-year-old, a student).

It balances my perspective when I know Melli asks for forgiveness in About Dhia. Balancing means I have observed that we have ups-and-downs in our lives. We may not always relate to Islam, but we could do it, slowly but surely (23-year-old, a student).

Julia hooks up on booze, drinking and dancing at bars but Julia still repents and asks God for forgiveness (22-year-old, a gas station attendant).

Gosh! At first, I thought Azwan lives in together with his girlfriend without legit marriage license. I panicked! But when he recites prayers, apologizing to God and calling off his sins, I cool down. Phew! (20-year-old, an online clothing store owner).

Because Melli sleeps with Rafie in About Dhia, I tried to calm down because I felt uncomfortable knowing their status as unmarried partners. I felt that this is not right in the eyes of society. But when he reads Quran and asks for forgiveness, I can now breathe (22-year-old, a student).

I screamed out loud after I found out Julia accepts Azwan's forgiveness. But why? I searched for the answer for a long time, but now I see the point. Julia just wants to move on. (20-year-old, a student). 
I went to Hajj last year and some things are still unclear. I am still searching the meaning of forgiving. But when I watched Adam \& Hawa, I can see why. (23-year-old, a housewife).

For many participants, forgiveness is one of the central aspects. Many of these issues on forgiveness in the popular TV fiction centered on the interplay between the fragmentation of self and communal beliefs, and the many disputes concerning cultural expectations and moral beliefs. Indeed, two participants (20 and 22-yearolds) explained that due to popular TV fiction discussing the idea of forgiveness, they were able to skip the scenes that challenged Malay norms. According to a participant, with rerun capabilities, scenes related to forgiveness could be played multiple times. In her own words, "About Dhia, to me, suggests a modern and upto-date TV series. If I watch guys and girls dancing in clubs or socializing intimately at home, with no legit causes, I definitely will skip the scenes. If they come back, regretting and asking for apologies, I am definitely in, because that is beautiful when people can accept each other for who they are and just get along."

These participants, along with many others, seem to convey forgiveness as points of reconciliation, acknowledging human beings' shortcomings. How they engage forgiveness to magnify discourses of reparation and expand this rhetoric of common humanity substantiate the need for repudiating past wrongdoings. We are reminded that forgiveness, as illuminated in participant accounts, also ensures the installation of peace and harmony (Hussain 93) and that these accounts might overlap with the notion of forgiveness as "informing strengths of character" (Martin 414-415). Perhaps, this is where the notion of democratic habits of mind comes into play because while audience members identify with forgiveness and are concerned about sociocultural norms, they also describe that such adhesion to imperfection reflects empathy about how others think and feel. What these audience members responded regarding forgiveness bear resemblance to Mezirow's notion of democratic habits of mind; according to Mezirow, forgiveness is a formulation of "dependable beliefs about our experience, assessing their contexts, and seeking informed decisions on the resulting insights" (4). Popular TV fiction allows for these audience members to negotiate these, implying that the self is a "work-inprogress," energized by multifaceted relationships of culture and society.

In a sense, audience member responses demonstrate examples of traits of democratic habits of mind in which the willingness to seek to understand and reach agreement until "new perspectives are encountered" (Mezirow 14) exist alongside imperfection. Their accounts of responding to how forgiveness is sought and implored-always in fear of not being connected and in fear of not being able to realize "human interests" (Mezirow 7)-provided a gaze into a world and the selves that are always constructing and re-constructing, offering continuous interaction between unofficial experiences, meanings, and expectations between 
human beings. In this context, Jerome Bruner highlights that forgiveness is humanizing as it magnifies "knowledge and values from multiple perspectives," (30) and reflects "understanding" and "emphatic listening" (Mezirow 12). That is, to forgive is to gesture towards the ways in which the selves and others participate in "constructive discourse to use the experience of others to assess reasons justifying" mistakes, atrocities, and perhaps, sins (Mezirow 8). These profound senses of reasonable agreement and the capacity to seek understanding are all grounded in the broader themes of imperfection; individual's misalignment and deviation, sinful or otherwise, will allow any reader or audience of popular TV fiction to come to terms with imperfection, a "word" that is universal, relatable, and human-centered.

\section{REPENTANCE AND SELF-REFORMATION}

As mentioned above, how audience members provide voices that coexist with imperfection forms the focus of this section. While popular TV fiction serves as a trivial visual display of cultural identity (Idrus et al., "Followership" 208), many audience member voices culled from our study appreciated content with what they could identify and resist those which do not (Idrus et al., "Power" 188). As in the following audience accounts, links made to issues of failure, suffering, and shame are recurring snapshots in this project, demonstrating varying levels of nuanced sociocultural life "catalogues." Like forgiveness above, popular TV fiction, as we shall see, is imbued with vicarious encounters that allow many ordinary audience members in this study to have a secondhand, everyday experience of what it must "feel" like to commit sins and repent, that are enclaved in the notions of Islamic framework and tradition. Whereas repentance is central to audience voices, many participants also refused to identify with scenes that oppose local, Malay norms. For instance, a participant highlighted, "Of course, Malay dramas show things like drinking and going to bars, but many will tell you that they repent" (21-year-old college student). In other words, it is through popular TV fiction that accounts related to imperfection can be raised to understand and (re)visit experiences with imperfect world(s):

Repentance makes us humane. Because no one is perfect, we repent. My children will know that regardless of sins they make, one can always apologize and pray, like what About Dhia shows us (20-year-old, unemployed).

There was a point in my life that I did not pray; I was not even close to doing anything nice to other people. Because of these, I have always thought I am abnormal, always different, until I was shunned from my Malay friends for not being religious. But Adam 
$\mathcal{E}$ Hawa shows me that it is okay to make mistakes because God hears me. I do not have to be shameful for what I am (24-year-old, college student).

About Dhia fascinates me. It keeps my life in focus. It shows I can have a balance. Although I am sinful, going to bars and drinking and stuff, I can also commit to praying and asking for forgiveness (23-year-old, a clerk).

I look up to Julia. As Julia is educated, so am I. She hangs out a lot with her friends at bar, I do that too. Eventually, in the TV show, she prays and repents. These flaws of Julia reflect who I am (23-year-old, college student).

I do not know about you, but Azwan in Julia repents (giggles). He repents after having lived with her girlfriend without actually getting married. I think it is okay because almost everyone is fallible (22-year-old, college student).

If people in America can forgive too, why can't we? I like Adam \& Hawa because it does not just show how frail and sinful we are in the eyes of God, but I think everyone needs one another (20-year-old, unemployed).

I think everyone went crazy having known Melli sleeps with Rafie in About Dhia. It even causes chaos and drama on blogs, I remember it was crazy because everyone thought it was against what Malays do. But I'm glad Melli repents after that. Praised to God (20-year-old, a college receptionist).

I was uncertain after knowing the fact that Julia accepts Azwan's apologies. Maybe she was forced to do it or maybe she felt guilty if she had not forgiven him; I don't know. But somehow Julia ends on a beautiful note when this happens. I felt happy (laughs) (24-year-old, a restaurant helper).

Why did Adam go to Hajj? He himself was a heavy drinker; he had many girlfriends earlier on. Perhaps he knows he makes a mistake by leaving his wife and he wants to make up for it? Who knows (24-year-old, a housewife).

Emerging issues arising from the interviews point to repentance. From conflicts between the self and culture, between moral and religious beliefs, to conflicts between individual and societal expectations, these issues are complex and they shape the contours of this discussion on repentance. This is further echoed by some other participants (20 and 21-year-olds) who highlighted that scenes on praying and performing pilgrimage motivated them to engage in popular TV fiction. In other words, they could fast-forward the popular TV fiction to scenes that empower Malay-Muslim norms. One of the participants commented: "Modern TV drama now has changed. No longer does it bore audience. Like me, I definitely skip to 
scenes that show how a true Muslim should be, someone who is not guilt-free. Someone who constantly finds her way to becoming a better Muslim each day" (2o-year-old, college student). In a way, many of these reactions link repentance to imperfection, as a repentant's duty is perhaps to do good deeds in order to offset "sins." Deviancy and human faults, according to Hussain Othman, are inevitable; they call for revitalization of re-nourishment and self-reformation, purifying the soul (93). These readings of participant accounts highlight pertinent intersection between "willingness to accept responsibility for the common good" and "openness" (Mezirow 14) so that a space of respecting and recognizing dignity (Mookherjee 1066) could surface. More broadly, audience accounts of their engagement with popular TV fiction can resemble a catalogue, where one could "flip" from various mistakes and sins to reforming one's self-dignity and self-restoration. Repentance takes up and claims a space where it allows participants in this study to relate to questions of religion that may construct values, leading us to their perspectives. More often than not, Mezirow adds, these cultural-religious beliefs and practices often "foster conformity" (Mezirow 8) to human nature's contexts, "sources, nature, and consequences" (Mezirow 7). More broadly, these audience accounts are composed of various competing stories; repentance in audience accounts is seen as stories of fear and uncertainty, revealing transformative practices, the determination to shatter atrocities and restore purification. Whether these accounts will absolve sins is a different issue, a matter that is still unresolved. But the interplay of reactions of how audience members respond to issues of imperfection, shifts important spaces, allowing them to identify with self-reformation that is always in construction. The multifaceted ways in which participants describe issues of imperfection here further illustrate how ordinary, everyday experiences give an opportunity for audience members to inscribe certain meaning to self and his/ her personhood in general. These readings further bear resemblance to the lens of democratic habits of mind; "full development of the human potential depend on values such as social justice and responsibility. It assumes that these values are basic to human need to constructively use the experience of others to understand, or make more dependable, the meaning of our experience" (Mezirow 16). Thus, by encountering issues on popular TV fiction, these audience accounts are reflexive of their unofficial, decentralized, continuous experience with failure, suffering, abnormalities, and deviation. These themes of forgiveness and repentance emerge in a form in which it allows audience members to flip through narratives of imperfection, presenting insights into a sense that imperfection cuts across spaces, people, and time. 


\section{CONCLUSION}

Earlier in this essay, we intended to argue that the shifting focus literary studies could present possibilities for recognizing disgrace, deviancy, and misalignment between the self/society and between private/public spheres through exploring twenty-firstcentury, non-institutionalized, non-state-endorsed, everyday experience. One of these depictions could be drawn from audience member accounts, engaging with popular TV fiction. These reactions by audience members, while advancing a civicminded discourse in (post)-popular TV fiction consumption, perhaps indicate mobilizations here in the ways in which imperfection is involved in (re)generating the self. Imperfection, as embedded in audience member accounts, has presented insights into unfolding, interactive spaces into what it means to engage with issues of moral and common ground capabilities. Emergence and development of themes of imperfection as expressed in audience member responses further open alternative spaces of stories, perhaps new ways of understanding the self and resilience, presenting a "window" into the dynamics of imperfection and vulnerabilities. More broadly, these examples of accepting apologies and coming to acts of purification and cleansing of the soul further demonstrate how they are relevant and spoken at all contexts as a recognition of fault, responsibility, and culpability, offsetting atrocities and sins. To paraphrase Julie McGonegal, to refuse and deny contexts of imperfection is "to foreclose on the promise of justice altogether" (141). It is through discussing imperfection that it will be possible to meet and address this promise. 


\section{Acknowledgment}

This research is made possible through a university grant funded by the National University of Malaysia (GUP-2016-067) and Research Acculturation Collaborative Effort (RACE/F3/SSI2/USIM/5). 


\section{Works Cited}

"Annual Report." Media Prima, 2013, https://www.mediaprima.com.my/investorcenter/ annualreport/2013/MPB_AR\%20201. Accessed 10 June 2014.

"Awrah." Alim, 2016, http://www.alim.org/search/node/awrah. Accessed 2 June 2017.

"Tonton Statistics." Tonton, 2014, https:/www.socialbakers.com/statistics/facebook/pages/ detail/141382189225413-tonton. Accessed 31 Oct. 2014.

Alasuutari, Pertti. "Three Phases of Reception Studies." Rethinking the Media Audience: The New Agenda, edited by Pertti Alasuutari, Sage, 1999, pp. 1-21.

Banks, David. "Islam and Inheritance in Malaya: Culture Conflict or Islamic Revolution?" American Ethnologist, vol. 3, no. 4, 1976, pp. 573-586.

Bradford, Simon, and Marilyn Clark. "Stigma Narratives: LGBT Transitions and Identities in Malta." International Journal of Adolescence and Youth, vol. 16, no. 2, 2011, pp. 179-200.

Bruner, Jerome. Acts of Meaning. Harvard UP, 1990.

Bryman, Alan. Quantity and Quality in Social Research. Routledge, 1988.

Chang, Wei-Wen. "Cultural Competence of International Humanitarian Workers." Adult Education Quarterly, vol. 57, no. 3, 2007, pp. 187-204.

Eisenhardt, Kathleen. "Building Theories from Case Study Research." The Academy of Management Review, vol. 14, no. 4, 1989, pp. 532-550. JSTOR, http://www.jstor.org/ stable/258557.

Hadad, Talia, and Elli Schachter. "Religious-lite': A Phenomenon and its Relevance to the Debate on Identity and Emerging Adulthood." Journal of Youth Studies, vol. 14, no. 8, 2011, pp. 853-869.

Hashim, Ruzy Suliza. Out of the Shadows: Women in Malay Court Narratives. Universiti Kebangsaan Malaysia Press, 2003.

Hussain, Othman. "Semantic Analysis of the Malay Islamic Concept of Man and the Universe." Journal of Islam in Asia, vol. 7, no. 1, 2010, pp. 87-107.

Idrus, Mohd Muzhafar. The Unconscious Malay Psyche: A Multidisciplinary Study of Cultural Identities in Selected Popular Malaysian Television Fiction. Universiti Kebangsaan Malaysia, PhD dissertation, 2015.

Idrus, Mohd Muzhafar, Ruzy Suliza Hashim, and Raihanah M. M. "Followership: Boosting Power and Position in Popular TV Fiction." GEMA Online Journal of Language Studies, vol. 15, no. 1, 2015, pp. 207-224. Universiti Kebangsaan Malaysia, doi: 10.17576/

GEMA-2015-1501-12.

-.. 'Globalization, Re-Discovery of the Malay 'Local', and Popular TV Fiction through Audience Narratives." 3 L: The Southeast Asian Journal of English Language Studies, vol. 22, no. 2, 2016, pp. 31-48. 
--. "Imagining Alternative Modernity: Negotiating Islamic-ness and Malay-ness on Popular TV Fiction." Asian Economic and Financial Review, vol. 4, no. 12, 2014, pp. 1798-1811. Conscientia Beam, doi: http://www.conscientiabeam.com/pdf-files/eco/3/ICBSSS156\%20AEFR-2014-4(12)-1798-1811.pdf

--. "Malay Cultural Identities: A Review." Humanities and Social Science Letters, vol. 2, no. 1, 2015, pp. 1-9.

--. "Power, Adat, and Popular TV Fiction Imaginary." Asian Journal of Social Sciences E Humanities, vol. 3, no. 4, 2014, pp. 186-196. doi: http://www.ajssh.leena-luna.co.jp/ AJSSHPDFs/Vol.3(4)/AJSSH2014(3.4-18).pdf

-. "Rediscovery of the Malay 'local:' Youth and TV Fiction in Malaysia." International Journal of Adolescence and Youth, vol. 22, no. 2, 2017, pp. 210-225.

Jarvis, Peter. Learning to Be a Person in Society. Routledge, 2009.

Johansson, Thomas, and Philip Lalander. "Doing Resistance - Youth and Changing Theories of Resistance." Journal of Youth Studies, vol. 15, no. 8, 2012, pp. 1078-1088. Taylor \& Francis Online, doi:10.1080/13676261.2012.693591.

Klein, Reva. Review of Beyond Individual and Collective Trauma: Intergenerational Transmission, Psychoanalytic Transmission and the Dynamics of Forgiveness by Clara Mucci. Psychodynamic Practice: Individuals, Groups and Organizations, vol. 22, no. 1, 2016, pp.79-77.

Lämsä, AnnaMaija, and Teppo Sintonen. "A Narrative Approach for Organizational Learning in a Diverse Organisation." Journal of Workplace Learning, vol. 18, no. 2, pp. 106-120.

Martin, Dahlia. "Gender, Malayness, and the Ummah: Cultural Consumption and MalayMuslim Identity." Asian Studies Review, vol. 38, no. 3, 2014, pp. 403-421.

McGonegal, Julie. "Imagining Justice: The Politics of Forgiveness and Reconciliation in Postcolonial Literature." Dissertation, McMaster University, 2004.

Mezirow, Jack. "Learning to Think Like an Adult: Core Concepts of Transformation Theory." Learning as Transformation: Critical Perspectives on a Theory in Progress, edited by Jack Mezirow and Associates, Jossey-Bass, 20oo, pp. 3-33.

Mookherjee, Monica. "Healing Multiculturalism: Middle-Ground Liberal Forgiveness in a Diverse Public Realm." Philosophia, vol. 44, no. 4, 2016, pp. 1057-1078.

Piaw, Chua Yan. Mastering Research Methods. McGraw Hill, 2012.

Poser, Benjamin. "Lower Than the Angels": The Unalienable Dignity of Human Imperfection. Undergraduate Thesis, Brandeis University, 2016.

Provencher, Ronald. "Comparison of Social Interaction Styles: Urban and Rural Malay Culture." The Anthology of Urban Environments, edited by Thomas Weaver and Douglas White, Society for Applied Anthropology, 1972, pp. 69-76.

Scarre, Geoffrey. "Forgiveness and Identification." Philosophia, vol. 44, no. 4, 2016, pp. 1021-1028.

Stoeber, Joachim. The Psychology of Perfectionism: Theory, Research, Applications. Routledge, 2018. 
Trimble, Lisa. "Transformative Conversations about Sexualities Pedagogy and the Experience of Sexual Knowing." Sex Education, vol. 9, no. 1, 2009, pp. 51-64.

Walter, Pierre. "Dead Wolves, Dead Birds, and Dead Trees: Catalysts for Transformative Learning in the Making of Scientist-Environmentalists." Adult Education Quarterly, vol. 63, no. 1, 2011, pp. 24-42.

Zainal, Kling. "Malay Family: Beliefs and Reality." Journal of Comparative Family Studies, vol. 26, no. 1, 1995, pp. 43-66. JSTOR, www.jstor.org/stable/41602366. 